\title{
Nitric Oxide Stimulates ACTH Secretion and the Transcription of the Genes Encoding for NGFI-B, Corticotropin-Releasing Factor, Corticotropin-Releasing Factor Receptor Type 1, and Vasopressin in the Hypothalamus of the Intact Rat
}

\author{
Soon Lee, C. Kwon Kim, and Catherine Rivier \\ The Clayton Foundation Laboratories for Peptide Biology, The Salk Institute, La Jolla, California 92037
}

\begin{abstract}
We investigated the effect of the intracerebroventricular injection of the nitric oxide (NO) donor 3-morpholino-sydnonimine $(\mathrm{SIN}-1)$ on the release of adrenocorticotropin hormone (ACTH) and the neuronal response of hypothalamic neurons responsible for this release. Rats that were administered SIN-1 showed significant elevations in plasma ACTH levels, a response that was virtually abolished by antibodies against corticotropinreleasing factor (CRF) and significantly blunted by vasopressin (VP) antiserum. SIN-1 also upregulated heteronuclear (hn) transcripts for CRF and VP and messenger RNA (mRNA) levels for the immediate early gene NGFI-B and for CRF receptor type 1 $\left(\mathrm{CRF}-\mathrm{R}_{1}\right)$ in the parvocellular portion of the paraventricular nucleus (PVN) of the hypothalamus. Blockade of prostaglandin synthesis with ibuprofen did not alter the ACTH or the PVN response to $\mathrm{SIN}-1$. The central nucleus of the amygdala and the
\end{abstract}

supraoptic nucleus, regions that are involved in autonomic adjustments to altered cardiovascular activity, also responded to SIN-1 with elevated NGFI-B mRNA levels. However, the only change in mean arterial blood pressure caused by this NO donor was a transient and modest increase. To our knowledge, this is the first demonstration that in the intact rat NO stimulates the activity of PVN neurons that control the hypothalamicpituitary-adrenal axis. It must be noted, however, that our results do not allow us to determine whether this effect was direct or mediated through PVN afferents. This study should help resolve the controversy generated by the use of isolated brain tissues to investigate the net effect of $\mathrm{NO}$ on hypothalamic peptide production.

Key words: nitric oxide; PVN; ACTH; CRF; vasopressin; HPA axis
Nitric oxide (NO) is an unstable gas whose role as an important ubiquitous neurotransmitter in the CNS has recently been recognized (Vincent, 1994; Garthwaite and Boulton, 1995; Snyder and Dawson, 1995). The first wave of studies focused on the involvement of this gas in processes related to synaptic transmission (such as long-term potentiation and memory) as well as in responses classically recognized as those depending on specific neurotransmitters (Bruhwyler et al., 1993). More recently, NO has been investigated as a possible modulator of neuroendocrine functions. The observation that NO synthase (NOS), the enzyme responsible for NO formation, is present in hypothalamic nuclei important for the hypothalamic-pituitary-adrenal (HPA) axis (Torres et al., 1993; Siaud et al., 1994; Villar et al., 1994; Vanhatalo and Soinila, 1995; Hatakeyama et al., 1996; Satta et al., 1998) suggested that this gas has a role in regulating adrenocorticotropin hormone $(\mathrm{ACTH})$ release. Our laboratory reported that blockade of NO formation with arginine derivatives such as $\mathrm{N}_{\omega}$ nitro-L-arginine-methylester (L-NAME) significantly blunted the ACTH response to physico-emotional stressors (Rivier, 1994). This finding suggested that endogenous NO exerts a stimulatory influence on circuitries leading to increased plasma

Received March 22, 1999; revised May 10, 1999; accepted June 11, 1999.

This work was supported by National Institutes of Health Grant MH 51774 and the Clayton Foundation for Research. C.R. is a senior research investigator. We are indebted to W. Kau, K. Scanlon, D. Bergen, M. Rosedale, and Y. Haas for expert technical support, and to Dr. R. Chan for his generous help with MAP and HR measurements.

Correspondence should be addressed to Dr. Catherine Rivier, The Salk Institute, The Clayton Foundation Laboratories for Peptide Biology, 10010 N. Torrey Pines Road, La Jolla, CA 92037.

Copyright (C) 1999 Society for Neuroscience 0270-6474/99/197640-08\$05.00/0
ACTH levels during these stressors. However, this hypothesis remains controversial, in part because the use of isolated hypothalamic tissues has yielded contradictory results with support for both a stimulatory and an inhibitory effect of NO on the release of corticotropin-releasing factor (CRF) (Costa et al., 1993; Sandi and Guaza, 1995; McCann et al., 1997; Tsuchiya et al., 1997).

Providing convincing evidence for the net effect of NO on CRF production is important in itself. Additionally, a better understanding of the functional relationship between NO and CRF takes on an increased urgency because of their potential role in mental disorders. Psychiatric illnesses such as depression and schizophrenia are characterized by increased circulating levels of the adrenal steroid cortisol, which is thought to reflect hypersecretion of hypothalamic CRF (Stokes and Sikes, 1991; Nemeroff, 1996; Heuser, 1998). Although the identification of the neurochemicals responsible for increased brain levels of this peptide is necessary for a better understanding of the molecular basis of these disorders (Gold et al., 1996), the mechanisms responsible for the elevated production of CRF in the hypothalamus and other brain areas have remained elusive. With regard to NO, a survey of the literature regarding its production in mental disorders indicates conflicting views, with reports of both elevated (Bloom, 1993) and decreased (Das et al., 1996; Bernstein et al., 1998) levels in the brains of schizophrenic patients. Although these findings emphasize the need for better knowledge of the functional links between NO and CRF production, they provide little information regarding potential specific and direct influences of NO on CRF-dependent pathways.

The purpose of the work we report here was therefore to 
determine the effect of an NO donor on ACTH release and the activity of neurons in the paraventricular nucleus (PVN) of the hypothalamus, which is the site that is important for HPA axis activity (Whitnall, 1993; Sawchenko et al., 1996; Watts, 1996).

\section{MATERIALS AND METHODS}

Animals. Adult male Sprague Dawley rats (180-200 gm on arrival) were kept under standard light (12 hr light/dark cycle; lights on at 6:30 A.M.) and feeding (rat chow and water ad libitum) regimens. Intracerebroventricular cannulae were implanted in the right lateral ventricle under ketamine/acepromazine/xylazine anesthesia (Rivest and Rivier, 1994) $7-10 \mathrm{~d}$ before the experiment. With the incisor bar placed at $3.3 \mathrm{~mm}$ below the interaural line (horizontal zero), the coordinates from bregma for the guide cannula were as follows: anteroposterior, -0.8 ; lateral, -1.4 ; dorsoventral, $-2.8 \mathrm{~mm}$. Correct placement of the intracerebroventricular cannulae was verified at the end of each experiment, and animals with incorrect placement were excluded from the data analysis. The animals also underwent aseptic insertion of a right jugular venous catheter under rapid ( $<3 \mathrm{~min}$ ) halothane anesthesia $48-72 \mathrm{hr}$ before testing (Rivest and Rivier, 1994). Animals were singly housed to prevent chewing of the cannulae and left undisturbed until the day of the experiment. On the morning of the experiment, the rats were placed in individual buckets, where they remained awake and freely moving. Their intravenous cannulae were connected to a tubing, itself attached to a syringe, which was used to inject the test compounds and to withdraw blood. For the intracerebroventricular cannulae, the dummy cannulae were removed and replaced with cannulae containing the treatments. Using these procedures, we can inject compounds in the general circulation and/or the brain ventricles, as well as remove blood, without handling the animals at any time. We routinely allow the animals to rest for $3 \mathrm{hr}$ after reconnection, and the experiments are performed between 9:00 A.M. and 12:00 P.M. to avoid a differential influence of the circadian rhythm. All protocols were approved by the Salk Institute IACUC.

Reagents. Although there are several well characterized NO donors that spontaneously release NO in vivo (Feelisch et al., 1989) and induce NO-dependent responses (Guevara-Guzman et al., 1994; Xu et al., 1995; Kapás and Krueger, 1996), we chose 3-morpholino-sydnonimine (SIN-1) because our preliminary studies indicated that it caused the most reliable and homogeneous responses. SIN-1 was purchased from Alexis Corporation (San Diego, CA) and diluted in sterile saline, $\mathrm{pH}$ 7.4. It was injected in a $5 \mu \mathrm{l}$ volume at the rate of $1 \mu \mathrm{l} / 10 \mathrm{sec}$. Blockade of prostaglandin $(\mathrm{PG})$ production was achieved with the cyclooxygenase inhibitor ibuprofen (purchased from Sigma, St. Louis, MO), which was administered at $12.5 \mathrm{mg} / \mathrm{kg}$ in saline, a dose that we have found to be fully effective in various paradigms (Rivier, 1995). CRF and VP antibodies were generated in our laboratory. Their specificity and validation have been reported elsewhere (Lee and Rivier, 1994; Rivier, 1994; Rivier and Shen, 1994). The antibodies were injected at levels shown to fully block the corresponding peptide (CRF antibodies, $0.2 \mathrm{ml} / \mathrm{kg}$; VP antibodies, $1.0 \mathrm{ml} / \mathrm{kg}$ ). Because the CRF antibodies were raised in sheep and the VP antibodies were raised in rabbits, control animals received injections of normal sheep or rabbit serum, respectively.

Brain preparation. Rats were deeply anesthetized with chloral hydrate, a drug that does not increase immediate early genes/peptides mRNA levels. They were then perfused transcardially with saline followed by $4 \%$ paraformaldehyde/ $0.1 \mathrm{~m}$ borate buffer, $\mathrm{pH} 9.5$. The brains were removed and post-fixed in $4 \%$ paraformaldehyde for $4-5 \mathrm{~d}$, then placed overnight in $10 \%$ sucrose $/ 4 \%$ paraformaldehyde $/ 0.1 \mathrm{~m}$ borate buffer. They were cut into $30 \mu \mathrm{m}$ coronal slices obtained at $120 \mu \mathrm{m}$ intervals throughout the hypothalamus and stored at $-20^{\circ} \mathrm{C}$ in a cryoprotectant solution $(50 \% 0.1$ M PBS, 30\% ethylene glycol, and 20\% glycerol) until histochemical analysis. Brains from control and experimental animals belonging to the same experiment were always analyzed in the same hybridization experiment. Hybridization histochemical localization of each transcript was performed using ${ }^{35} \mathrm{~S}$ - or ${ }^{33} \mathrm{P}$-labeled cRNA probes prepared as described previously (Lee and Rivier, 1997, 1998). A sense probe was used as a control for nonspecific signal in some adjacent sections for in situ hybridization.

Quantitative analysis of in situ hybridization results. Semiquantitative densitometric analysis of hybridization signals for RNAs of interest was performed in nuclear emulsion-dipped slides. Brain paste standards containing serial dilutions of ${ }^{35} \mathrm{~S}$-UTP or ${ }^{33} \mathrm{P}$-UTP, used for quantification of mRNA signal, were prepared concurrently to ensure that optical density was found within the linear range of the standard curve (Chan and Sawchenko, 1995). In addition, analyses with emulsion-coated slides were performed with two to three different exposure times to confirm that signals were not saturated. Densitometric analyses of autoradiographic signals were performed over the confines of cells within the PVN using a Leitz optical system coupled to a Macintosh II computer and Image software (version 1.61, W Rasband, NIH). Dark-field measurements for the parvocellular (p) and magnocellular (m) divisions of the PVN were obtained separately, as reported previously (Lee and Rivier, 1994; Lee et al., 1995). Gray-level measurements [optical density (OD)] were taken under dark-field illumination of hybridized sections over the medial pPVN or mPVN, the supraoptic nucleus (SON), or the central nucleus of the amygdala $(\mathrm{CeA})$, as defined by redirected sampling from the corresponding Nissl-stained sections under bright-field images. Data were expressed in gray scale values of 1-256. All gray-level measurements were corrected for background, which corresponded to the areas immediately adjacent to those under study. Signals were measured in both sides of the brain, and mean values for all animals (four to six per group) were determined in three to four sections for each rat throughout the PVN, CeA, and SON.

Mean arterial blood pressure (MAP) and heart rate (HR) measurements. Each animal was implanted with an indwelling right femoral arterial catheter for monitoring of MAP and HR. Surgery was performed at least $7 \mathrm{~d}$ after intracerebroventricular cannulation. The catheter was connected to the blood pressure apparatus (Model RS 3200; Gould, Valley View, OH) $24 \mathrm{hr}$ later, and each rat was allowed to habituate for $3 \mathrm{hr}$ before the intracerebroventricular drug treatment. MAP and HR were
A

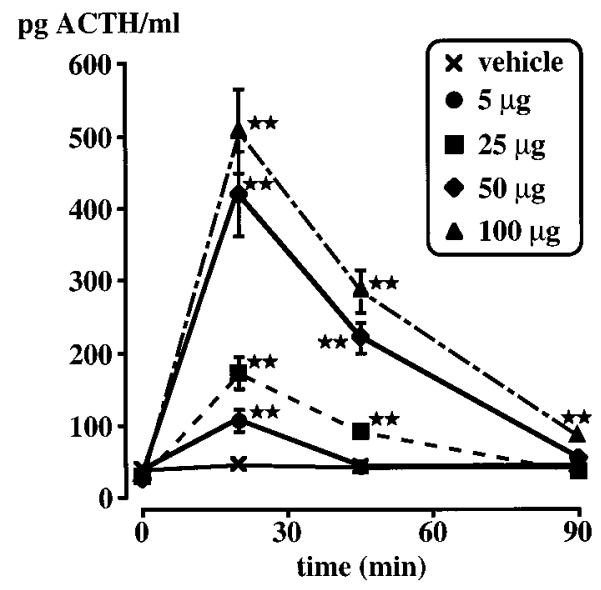

B

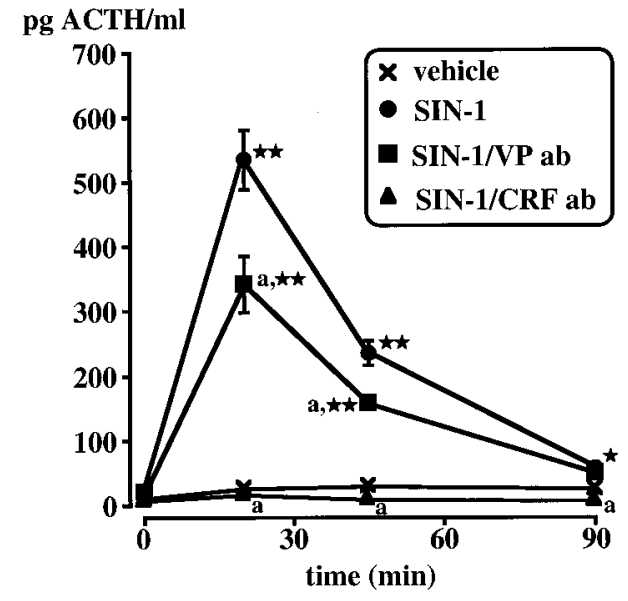

Figure 1. A, Effect of the intracerebroventricular injection of the vehicle or several doses of SIN-1 $(5-100 \mu \mathrm{g})$ on plasma ACTH levels. B, Role of CRF and VP in the ACTH response to SIN-1. Antibodies $(a b)$ to CRF or VP or their corresponding vehicle (normal sheep and normal rabbit serum, respectively) were injected intravenously $15 \mathrm{~min}$ before SIN-1 (50 $\mu \mathrm{g}$, i.c.v.). Each point represents the mean \pm SEM of five to six rats. ${ }^{*} p<0.05$ and ${ }^{*} p<0.01$ versus vehicle. $a, p<0.01$ versus SIN-1. 
monitored continuously in freely moving rats for $30 \mathrm{~min}$ before and 90 min after intracerebroventricular treatment.

ACTH assay. Plasma ACTH levels were determined by a commercially available two-site immunoradiometric assay (Allegro kit, Nichols Institute, San Juan Capistrano, CA) that has been validated for the measurement of rat ACTH (Rivier and Shen, 1994). The lower detection limit of this assay is $15 \mathrm{pg} / \mathrm{ml}$, and samples in which ACTH levels were $<15$ $\mathrm{pg} / \mathrm{ml}$ were assigned that value for statistical analysis. The intra-assay and interassay coefficients of variation are 7 and $<15 \%$, respectively.

Statistical analysis. For blood samples, statistical analysis was performed by one- and two-way factorial ANOVA and/or Dunn-Sidak procedure for contrasting means. Data of in situ hybridization experiments are expressed as OD (arbitrary units) and were analyzed by ANOVA and post hoc comparisons using Scheffe's test (Statview II). All brain sections hybridized at the same time were included in the same statistical test.

\section{RESULTS}

\section{Effect of the intracerebroventricular injection of SIN-1 on plasma ACTH levels}

These experiments were designed to establish the effective doses of intracerebroventricular SIN-1 as well as the time course of the HPA axis response. Although the intracerebroventricular injection of the vehicle did not significantly alter baseline ACTH levels, SIN-1 significantly $(p<0.01)$ increased this parameter (Fig. 1A).

\section{Role of CRF, VP, and PGs on the ACTH response to SIN-1}

CRF, VP, and PGs have all been implicated in the regulation of the HPA axis response to various stimuli (Rivier and Plotsky, 1986; Antoni, 1993; Turnbull and Rivier, 1996; Watts, 1996). To determine the role of $\mathrm{CRF}$ or $\mathrm{VP}$ in the $\mathrm{ACTH}$ response to intracerebroventricular SIN-1 $(50 \mu \mathrm{g})$, rats were injected intravenously with antibodies to CRF or VP $15 \mathrm{~min}$ before the NO donor. Control animals received normal sheep serum (control for CRF antibodies) or normal rabbit serum (control for VP antibodies) $15 \mathrm{~min}$ before intracerebroventricular vehicle. Immunoneutralization of endogenous CRF virtually abolished $(p<0.01)$ the ACTH response to the NO donor, whereas VP antibodies partially but significantly $(p<0.01)$ decreased this response (Fig. $1 B$ ). Ibuprofen, administered intravenously 15 min before SI N-1, had a modest effect that was not statistically significant (data not shown).

\section{Effect of the intracerebroventricular injection of SIN-1 on PVN neuronal responses}

For all signals examined in the present study, the times at which the animals were killed were based on our previous experience of the time course of these transcripts' response under various experimental conditions (Lee and Rivier, 1994; Lee et al., 1994, 1995). On the basis of the results of Figure 1, we chose to inject $50 \mu \mathrm{g}$ of SIN-1.

\section{Immediate early gene}

NGFI-B cDNA encodes proteins that are transcriptional regulators, which then bind specific DNA sequences to modulate the expression of their target genes (Evans, 1988). NGFI-B is classically used as an index of increased neuronal activation (Morgan and Curran, 1991; Chan et al., 1993) and, importantly for our work, stimulates transcription via NGFI-B response element (Wilson et al., 1991) for which the promoter region of the rat CRF and VP gene have a consensus sequence (Mohr and Richer, 1990; Wilson et al., 1991). Compared with vehicle-injected controls, the PVN of rats administered SIN-1 displayed significantly $(p<$ 0.01 ) increased mRNA levels of NGFI-B in both pPVN and
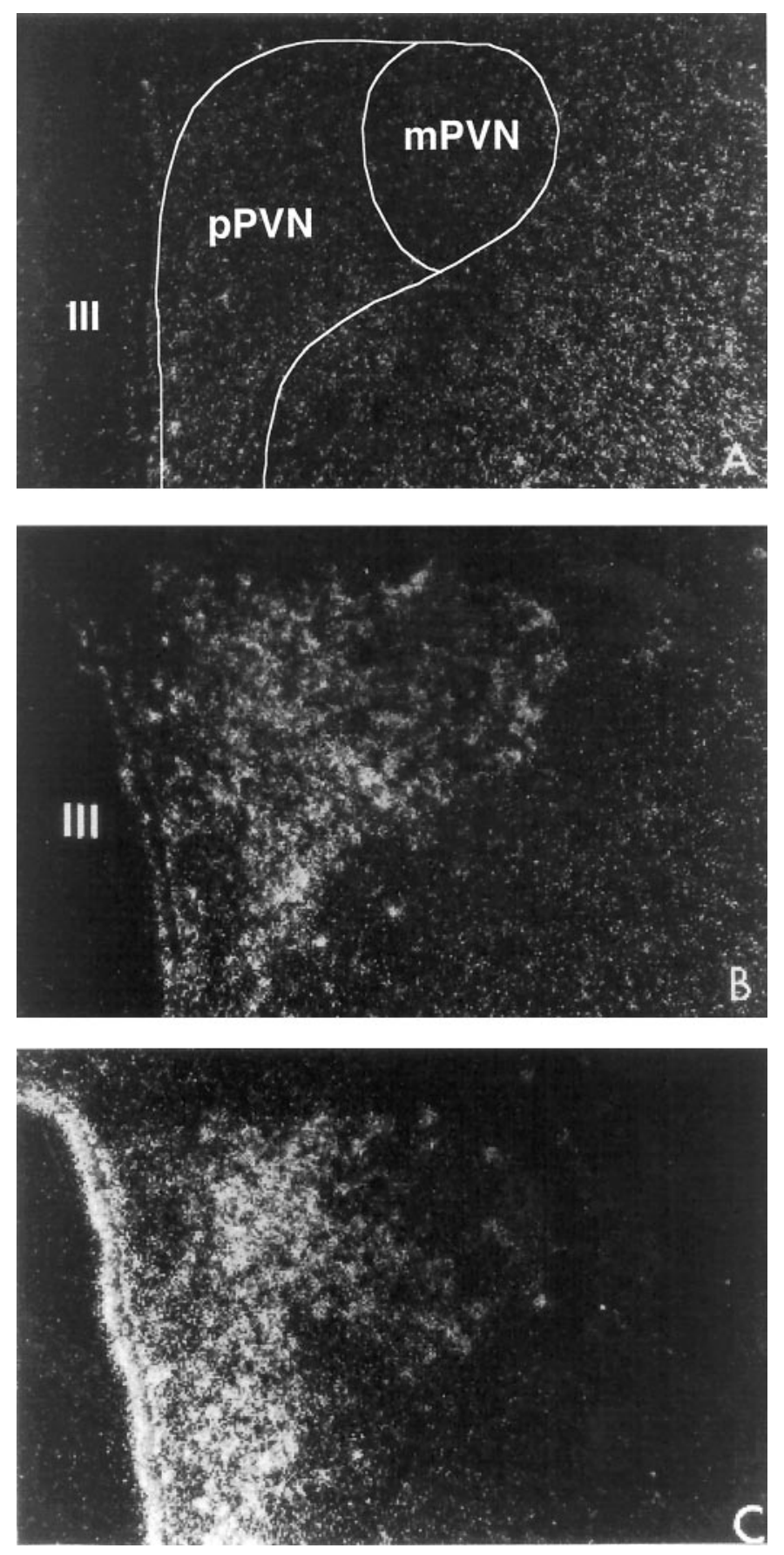

Figure 2. Dark-field photomicrographs illustrating the effect of the intracerebroventricular injection of the vehicle or SIN-1 $(50 \mu \mathrm{g})$ on the PVN neuronal response, expressed in terms of changes in NGFI-B mRNA levels. $A$, Vehicle; $B, 15$ min after intracerebroventricular SIN-1; $C, 45 \mathrm{~min}$ after intracerebroventricular SIN-1. III, Third ventricle. Magnification: $340 \times$.

mPVN, as well as in SON and CeA at 15 and 45 min after treatment (Figs. 2, 3, Table 1).

\section{$C R F$ and $V P$}

In the pPVN, SIN-1 significantly $(p<0.01)$ induced the appearance of CRF hnRNA within $15 \mathrm{~min}$, indicating rapidly upregulated CRF biosynthesis in this region of the hypothalamus (Fig. 4, Table 2). VP hnRNA levels also significantly $(p<0.01)$ increased 

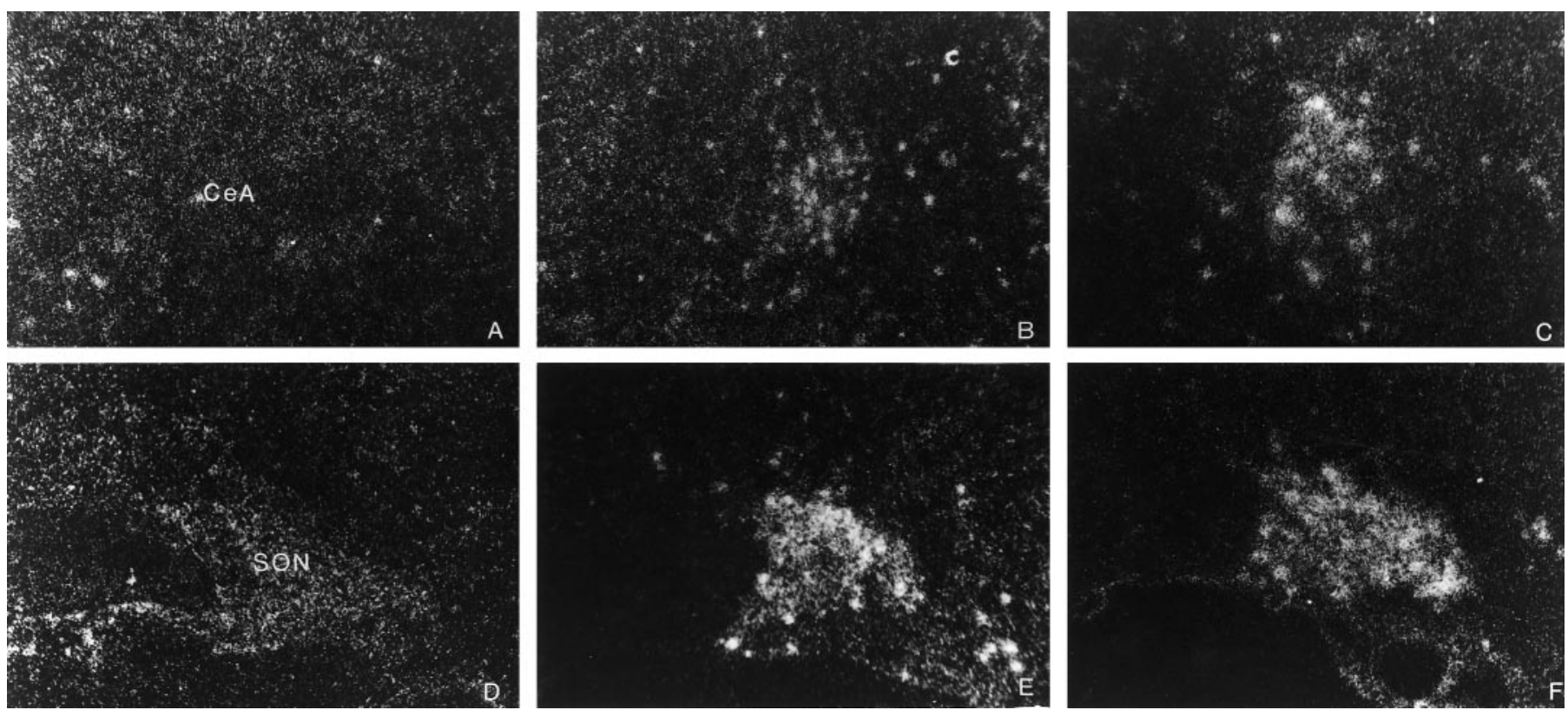

Figure 3. Dark-field photomicrographs illustrating the effect of the intracerebroventricular injection of the vehicle or SIN-1 (50 $\mu \mathrm{g})$ on the neuronal response of the central nucleus of the amygdala (CeA, top panels) and supraoptic nucleus (SON, bottom panels), expressed in terms of changes in NGFI-B mRNA levels. CeA: $(A)$ vehicle, $(B) 15$ min after intracerebroventricular SIN-1, $(C) 45$ min after intracerebroventricular SIN-1; SON: $(D)$ vehicle, $(E)$ 15 min after intracerebroventricular SIN-1, $(F) 45$ min after intracerebroventricular SIN-1. Magnification: $340 \times$.

Table 1. Statistical analysis of the results presented in Figures 2 and 3

\begin{tabular}{|c|c|c|c|c|}
\hline \multirow[b]{2}{*}{$\begin{array}{l}\text { NGFI-B } \\
\text { mRNA }\end{array}$} & \multicolumn{4}{|c|}{ Treatment } \\
\hline & $\begin{array}{l}\text { Vehicle } \\
(15 \text { min })\end{array}$ & $\begin{array}{l}\text { Vehicle } \\
\text { (45 min) }\end{array}$ & $\begin{array}{l}\text { SIN-1 } \\
(15 \text { min })\end{array}$ & $\begin{array}{l}\text { SIN-1 } \\
\text { (45 min) }\end{array}$ \\
\hline pPVN & $6.2 \pm 1.2$ & $3.2 \pm 1.3$ & $22.8 \pm 1.2^{*}$ & $17.2 \pm 1.2$ \\
\hline $\mathrm{mPVN}$ & $7.5 \pm 2.4$ & $2.3 \pm 0.6$ & $17.2 \pm 1.2^{*}$ & $19.0 \pm 2.1^{*}$ \\
\hline $\mathrm{CeA}$ & ND & $3.7 \pm 0.8$ & $14.7 \pm 2.1^{*}$ & $16.5 \pm 1.3^{*}$ \\
\hline SON & ND & $14.9 \pm 1.4$ & $23.5 \pm 1.2^{*}$ & $23.7 \pm 1.9$ \\
\hline
\end{tabular}

Data are expressed in terms of OD (arbitrary units) for NGFI-B mRNA levels at 15 and $45 \mathrm{~min}$ after the intracerebroventricular injection of SIN-1 $(50 \mu \mathrm{g})$. Each value represents the mean \pm SEM of four to five replicates. ${ }^{*} p<0.01$ versus vehicle at the corresponding time. pPVN, Parvocellular division of the paraventricular nucleus; $\mathrm{mPVN}$, magnocellular division of the paraventricular nucleus; $\mathrm{CeA}$, central nucleus of the amygdala; SON, supraoptic nucleus; ND, not determined.

in the pPVN $3 \mathrm{hr}$ after treatment, whereas changes in the mPVN were small and not statistically significant.

\section{$C R F-R_{1}$}

SIN-1 significantly $(p<0.01)$ increased CRF- $\mathrm{R}_{1}$ mRNA levels in the pPVN 3 hr after treatment (vehicle, $5.4 \pm 4.0$; SIN-1, $18.9 \pm$ $0.8 ; p<0.01)$. There were no measurable $\mathrm{CRF}-\mathrm{R}_{1}$ transcripts in the mPVN (data not shown).

\section{Effect of PGs on the PVN neuronal response to SIN-1}

Blockade of PG synthesis with ibuprofen did not significantly

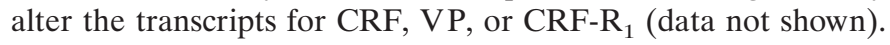

\section{Effect of the intracerebroventricular injection of SIN-1 on MAP and HR}

The vehicle did not significantly alter basal MAP, whereas the intracerebroventricular injection of SIN-1 $(50 \mu \mathrm{g})$ induced a significant $(p<0.05-0.01)$ although transient increase in MAP (Fig. 5). MAP measured for up to $75 \mathrm{~min}$ after the last point illustrated on the figure failed to indicate any further effect of
SIN-1 (data not shown). Changes in HR were minimal (data not shown).

\section{DISCUSSION}

We show here that the intracerebroventricular injection of the NO donor SIN-1 significantly increased plasma ACTH levels and upregulated the gene expression of NGFI-B, CRF, and VP, as well as $C R F-R_{1}$, in the PVN. The functional importance of the increased levels of CRF and VP transcripts was then demonstrated by the ability of their corresponding antibodies to abolish or blunt, respectively, the ACTH response to the NO donor. Although results obtained with CRF antibodies were not unexpected in view of the pivotal influence of this peptide on the regulation of $\mathrm{ACTH}$ release, the effect of brain $\mathrm{NO}$ on VP release remains controversial, with evidence for both very shortlived stimulatory (Ota et al., 1993) and inhibitory (Kadekaro et al., 1997; Liu et al., 1998) effects. The ability of VP antibodies to reduce the ACTH response to SIN-1 therefore supports the concept that NO releases VP.

To our knowledge, this is the first report of a direct effect of NO on PVN neuronal activity in the intact rodent, and it may help put to rest at least some of the controversy that has surrounded the net effect of $\mathrm{NO}$ on $\mathrm{CRF}$ and VP production. In endocrinology, work performed in isolated cells has provided useful mechanistic information. However, the fact that these tissues are isolated from their normal environment, in terms of both the hormonal/humoral milieu and the presence of afferent pathways, makes functional results obtained in these preparations difficult to extend to the whole animal. In the case of NO we have provided strong evidence, by investigating the consequence of blocking NO formation (Rivier, 1994; Turnbull et al., 1998) and by showing the effect of intracerebroventricular SIN-1 (present work), that $\mathrm{NO}$ exerts a stimulatory effect on PVN neurons that are important for the ACTH response to neurogenic stress. It should be noted that in contrast, we showed earlier that NO 

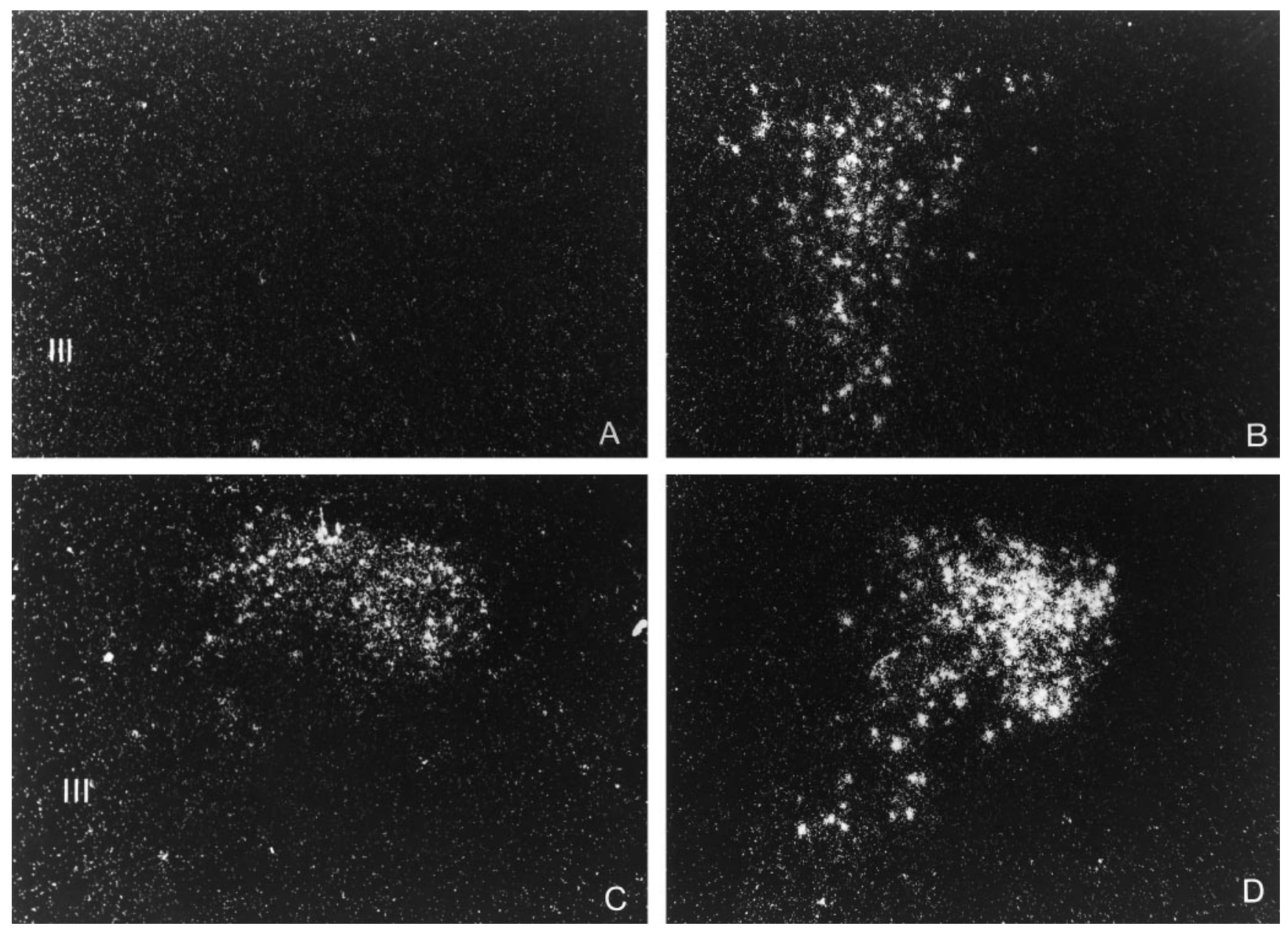

Figure 4. Dark-field photomicrographs illustrating the effect of the intracerebroventricular injection of the vehicle or SIN-1 (50 $\mu \mathrm{g})$ on CRF and VP hnRNA levels in the PVN. CRF hnRNA (top panels) and VP hnRNA (bottom panels) levels were measured 15 min and 3 hr after the intracerebroventricular injection of SIN-1, respectively. CRF hnRNA: $(A)$ vehicle, $(B)$ SIN-1; VP hnRNA: $(C)$ vehicle, $(D)$ SIN-1. III, Third ventricle. Magnification: $340 \times$.

\begin{tabular}{l}
\hline \multicolumn{2}{l}{ Table 2. Statistical analysis of the results presented in Figure 4} \\
\\
\begin{tabular}{lll} 
Transcripts & Vehicle & SIN-1 \\
\hline $\begin{array}{l}\text { CRF hnRNA }(15 \mathrm{~min}) \\
\text { pPVN }\end{array}$ & $7.9 \pm 1.2$ & $26.2 \pm 3.7^{*}$ \\
VP hnRNA (3 hr) & & \\
pPVN & $11.6 \pm 0.8$ & $18.9 \pm 1.3^{* *}$ \\
mPVN & $43.4 \pm 7.5$ & $57.4 \pm 8.4$
\end{tabular} \\
\hline
\end{tabular}

$\overline{\text { Data are expressed in terms of OD (arbitrary units). CRF hnRNA and AVP hnRNA }}$ were measured $15 \mathrm{~min}$ and $3 \mathrm{hr}$ after SIN-1 (50 $\mu \mathrm{g}$ intracerebroventricular). Transcripts of CRF and its receptor are only located in the pPVN, whereas VP transcripts are found in both pPVN and mPVN. Each value represents the mean \pm SEM of four replicates. ${ }^{*} p<0.05$ versus vehicle; ${ }^{*} p<0.01$ versus vehicle. pPVN, Parvocellular division of the paraventricular nucleus; mPVN, magnocellular division of the paraventricular nucleus.

inhibits pituitary response to blood-borne cytokines, either by interfering with peptide release from nerve terminals or by blunting the effect of VP on the corticotrophs (Rivier and Shen, 1994; Rivier, 1995; Turnbull and Rivier, 1996). These observations point to the difficulty of using valid isolated tissue preparations to probe the role of this gas on the HPA axis and to the need to carefully evaluate which studies and preparations provide the most meaningful information regarding the importance of NO in the intact animal.

Intracerebroventricular SIN-1 also significantly augmented transcript levels of the immediate early gene NGFI-B in the central nucleus of the amygdala and the supraoptic nucleus, regions that are involved in autonomic responses (Loewy, 1990; Spyer, 1990). These results agree with reports that NO donors such as sodium nitroprusside or nitroglycerin activate a widespread set of neurons that control not only endocrine but also autonomic and limbic pathways, such as the nucleus tractus solitarius, ventrolateral medulla, and parabrachial nucleus (Tassorelli et al., 1997). The pattern of many of these responses is similar to that observed after hypotensive hemorrhage (Chan and Sawchenko, 1994), which raised the possibility that SIN-1induced activation of the HPA axis might have been, at least in part, secondary to a change in blood pressure (BP) (Chan et al., 1993). The intracerebroventricular injection of L-NAME has been shown to increase BP (Kadekaro et al., 1994), which suggests that brain NO could indeed cause hypotension. However, in agreement with work based on the intracerebroventricular or intravenous injection of several NO donors (Nurminen and Vapaatalo, 1996), we found that a dose of intracerebroventricular SIN-1 that significantly activated the HPA axis produced only a modest and short-lived increase in BP. In view of the fact that 


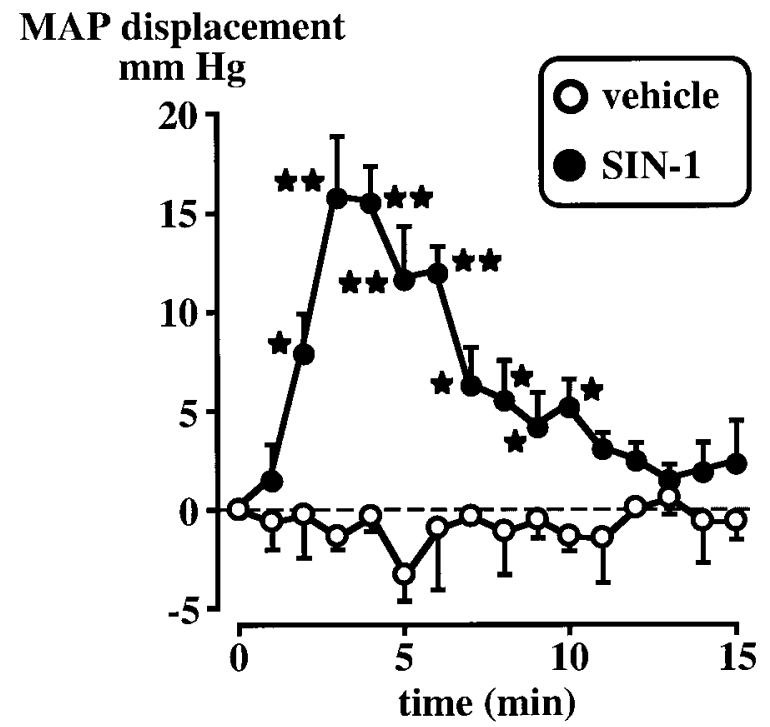

Figure 5. Effect of the intracerebroventricular injection of the vehicle or SIN-1 $(50 \mu \mathrm{g})$ on MAP displacement $(\mathrm{mm} \mathrm{HG})$ from the pre-drug baseline $(0 \mathrm{~min}$, which represents the mean of 5 measurements at 1 min intervals). Each point represents the mean \pm SEM of four to five rats. ${ }^{*} p<0.05$ and ${ }^{* *} p<0.01$ versus vehicle.

hypertensive challenges are not thought to upregulate PVN activity (Li and Dampney, 1994), our results make it highly unlikely that SIN-1 stimulated the HPA axis by elevating BP. With regard to the apparent discrepancy between the ability of both NO donors (Nurminen and Vapaatalo, 1996; and present work) and L-NAME (Kadekaro et al., 1994) to increase BP, it must be noted that according to a recent study, $>50 \%$ of substances injected intracerebroventricularly leak to the periphery within 5 min (Maness et al., 1998). It is therefore possible that the increase in BP observed after the central injection of a relatively large dose of L-NAME (Kadekaro et al., 1994) may have been caused, at least in part, by the peripheral effect of this compound on cardiovascular parameters.

The final mechanism that we investigated was the role of PGs. These compounds are known to modulate some, although not all, aspects of HPA axis activity. For example, PG blockers such as indomethacin and ibuprofen totally block the ACTH response to intracerebroventricularly injected cytokines (Rivier and Vale, 1991) and psychological stressors (Morimoto et al., 1991), but not to mild electrofootshocks (C. Rivier, unpublished observations). These effects are not exerted at the level of the pituitary response to CRF (Bugajski et al., 1996) and therefore presumably involve the inhibition of higher circuitries. In addition, NO activates lipooxygenase and cyclooxygenase enzymes (Salvemini et al., 1993; Sautebin et al., 1995) and could therefore alter the HPA axis through this mechanism. We show here that the elimination of PGs had little effect on the stimulatory influence of NO on the HPA axis.

Where did SIN-1 act to activate the HPA axis? This question has two aspects: one linked to the amount of NO generated by a pharmacological donor and its relevance to physiologically produced NO, and the other linked to the anatomical identity of the responding neurons. The first issue is difficult to address because measurement of NO release in vivo remains fraught with difficulties and artifacts. Using the hemoglobin-trapping technique, we detected baseline NO levels of $\sim 50-100 \mathrm{~nm}$ in the PVN, which increased to $\sim 200 \mathrm{~nm}$ after intravenous lipopolysaccaride (LPS) treatment (R. M. Uribe and C. Rivier, unpublished observations). However, until we have information regarding the NO concentrations generated by the doses of SIN-1 that we used, we do not know how these concentrations relate to NO released under stressful conditions. The second issue pertains to the site of action of NO. One reasonable possibility, of course, is that its stimulatory effect is exerted on the PVN itself. In support of this hypothesis, we recently observed that the microinfusion of the NO donor sodium nitroprusside dorsal to the PVN area, which is not known to include any PVN afferents, significantly increased the ACTH response to endotoxin injection (Uribe and Rivier, unpublished observations). The presence of NOS in PVN CRF and VP cell bodies (Torres et al., 1993; Siaud et al., 1994) suggests that under physiological conditions, NO can influence these neurons in an autocrine manner. If, on the other hand, intracerebroventricular SIN-1 activated the PVN by acting on its afferents, potential candidates should be those that can respond to NO and therefore express cGMP, which is considered a functional NO receptor (Snyder and Dawson, 1995). However, the wide distribution of this enzyme (Vincent, 1995) does not provide useful guidance in this regard. Although NO that is formed in response to SIN-1 does not depend on the presence of NOS, we used this compound to study the endocrine responses that are induced by increased NO levels. Consequently, a valid criterion to identify the PVN afferents that might be involved in our model is the presence of NOS in this circuitry. PVN afferents are well defined (Swanson, 1991; Watts, 1996; Champagne et al., 1998; Horvath, 1998; Li and Sawchenko, 1998), and comparison between their localization and that of NOS (Endoh et al., 1994; Blottner et al., 1995; Iwase et al., 1998; Rothe et al., 1998) suggests that the dorsomedial and lateral hypothalamus, preoptic nucleus, dorsal raphe nucleus, nucleus of the solitary tract, and laterodorsal tegmental nucleus, in particular, are potential candidates. NOSpositive neurons have also been observed in the amygdala, and these neurons were reported to send terminals to the PVN (Tanaka et al., 1997). However, although functional importance of the amygdala for the HPA axis activity has received support (Beaulieu et al., 1987; Bohus et al., 1996; Goldstein et al., 1996; Marcilhac and Siaud, 1996; Feldman et al., 1998), the general view is that amygdala-PVN connections are indirect and sparse (Swanson, 1991; Sawchenko et al., 1996; Champagne et al., 1998). Further investigation will therefore be necessary to determine whether NO produced in the amygdala plays a role in the activity of the HPA axis.

In conclusion, we have shown that the intracerebroventricular injection of the NO donor SIN-1 significantly increased ACTH release and stimulated the neuronal activity of CRF and VP cell bodies in the pPVN. Although additional work is needed to localize the site of action of this gas, our results provide solid evidence that in the intact animal, the net effect of NO on the PVN neurons that regulate ACTH release is stimulatory. These results should help resolve the controversy generated by the use of isolated tissues in studies that investigate the response of CRF and VP cell bodies exposed to NO donors and inhibitors.

\section{REFERENCES}

Antoni FA (1993) Vasopressinergic control of pituitary adrenocorticotropin secretion comes of age. Front Neuroendocrinol 14:76-122.

Beaulieu S, DiPaolo T, Cote J, Barden N (1987) Participation of the central amygdaloid nucleus in the response of adrenocorticotropin secretion to immobilization stress: opposing roles of the noradrenergic and dopaminergic systems. Neuroendocrinology 45:37-46. 
Bernstein H-G, Stanarius A, Baumann B, Henning H, Krell D, Danos P, Falkai P, Bogerts B (1998) Nitric oxide synthase-containing neurons in the human hypothalamus: reduced number of immunoreactive cells in the paraventricular nucleus of depressive patients and schizophrenics. Neuroscience 83:867-875.

Bloom F (1993) Advancing a neurodevelopment origin for schizophrenia. Arch Gen Psychiatry 50:224-227.

Blottner D, Grozdanovic Z, Gossrau R (1995) Histochemistry of nitric oxide synthase in the nervous system. Histochem J 27:785-811.

Bohus B, Koolhaas JM, Luiten PGM, Korte SM, Roozendaal B, Wiersma A (1996) The neurobiology of the central nucleus of the amygdala in relation to neuroendocrine and autonomic outflow. In: Emotional motor system (Holstege G, Bandler R, Saper CB, eds), pp 447-460. Amsterdam: Elsevier Science.

Bruhwyler J, Chleide E, Liegeois JF, Carreer F (1993) Nitric oxide: a new messenger in the brain. Neurosci Biobehav Rev 17:373-384.

Bugajski J, Olowska A, Gadek-Michalska A, Borycz J, Glod R, Bugajski A (1996) Effect of indomethacin on the CRH- and VP-induced pituitary-adrenocortical response during social stress. Life Sci 58:PL67-PL72.

Champagne D, Beaulieu J, Drolet G (1998) CRFergic innervation of the paraventricular nucleus of the rat hypothalamus: a tract-tracing study. J Neuroendocrinol 10:119-131.

Chan R, Sawchenko P (1995) Hemodynamic regulation of tyrosine hydroxylase messenger RNA in medullary catecholamine neurons: a $c$-fos-guided hybridization histochemical study. Neuroscience 66:377-390.

Chan RKW, Sawchenko PE (1994) Spatially and temporally differentiated patterns of $c$-fos expression in brainstem catecholaminergic cell groups induced by cardiovascular challenges in the rat. J Comp Neurol 348:433-460.

Chan RKW, Brown ER, Ericsson A, Kovács KJ, Sawchenko PE (1993) A comparison of two immediate-early genes, c-fos and NGFI- $\beta$, as markers for functional activation in stress-related neuroendocrine circuitry. J Neurosci 13:5126-5138.

Costa A, Trainer P, Besser M, Grossman A (1993) Nitric oxide modulates the release of corticotropin-releasing hormone from the rat hypothalamus in vitro. Brain Res 605:187-192.

Das I, Khan NS, Puri BK, Hirsch SR (1996) Elevated endogenous nitric oxide synthase inhibitor in schizophrenic plasma may reflect abnormalities in brain nitric oxide production. Neurosci Lett 215:209-211.

Endoh M, Maiese K, Wagner JA (1994) Expression of the neural form of nitric oxide synthase by CA1 hippocampal neurons and other central nervous system neurons. Neuroscience 63:679-689.

Evans RM (1988) The steroid and thyroid hormone receptor superfamily. Science 240:889-895.

Feelisch M, Ostrowski J, Noack E (1989) On the mechanism of NO release from sydnonimines. J Cardiovasc Pharamacol 14[Suppl 11]:S13-S22.

Feldman S, Newman ME, Gur E, Weidenfeld J (1998) Role of serotonin in the amygdala in hypothalamo-pituitary-adrenocortical responses. NeuroReport 9:2007-2010.

Garthwaite J, Boulton CL (1995) Nitric oxide signaling in the central nervous system. Annu Rev Physiol 57:683-706.

Gold PW, Wong M-L, Chrousos GP, Licinio J (1996) Stress system abnormalities in melancholic and atypical depression: molecular, pathophysiological, and therapeutic implications. Mol Psychiat 1:257-264.

Goldstein LE, Rasmusson AM, Bunney BS, Roth RH (1996) Role of the amygdala in the coordination of behavioral, neuroendocrine, and prefrontal cortical monoamine responses to psychological stress in the rat. J Neurosci 16:4787-4798.

Guevara-Guzman R, Emson PC, Kendrick KM (1994) Modulation of in vivo striatal transmitter release by nitric oxide and cyclic GMP. J Neurochem 62:807-810.

Hatakeyama S, Kawai Y, Ueyama T, Senba E (1996) Nitric oxide synthase-containing magnocellular neurons of the rat hypothalamus synthesize oxytocin and vasopressin and express Fos following stress stimuli. J Chem Neuroanat 11:243-256.

Heuser I (1998) The hypothalamic-pituitary-adrenal system in depression. Pharmacopsychiatry 31:10-13.

Horvath TL (1998) An alternate pathway for visual signal integration into the hypothalamo-pituitary axis: retinorecipient intergeniculate neurons project to various regions of the hypothalamus and innervate neuroendocrine cells including those producing dopamine. J Neurosci 18:1546-1558.

Iwase K, Iyama K-I, Akagi K, Yano S, Fukunaga K, Miyamoto E, Mori M, Takiguchi M (1998) Precise distribution of neuronal nitric oxide synthase mRNA in the rat brain revealed by non-radioisotopic in situ hybridization. Mol Brain Res 53:1-12.

Kadekaro M, Terrell ML, Harmann P, Summy-Long JY (1994) Central inhibition of nitric oxide synthase attenuates water intake but does not alter enhanced glucose utilization in the hypothalamoneurohypophysial system of dehydrated rats. Neurosci Lett 173:115-118.

Kadekaro M, Liu H, Terrell M, Gestl S, Bui V, Summy-Long J (1997) Role of NO on vasopressin and oxytocin release and blood pressure responses during osmotic stimulation in rats. Am J Physiol 273:R1024-R1030.

Kapás L, Krueger JM (1996) Nitric oxide donors SIN-1 and SNAP promote nonrapid-eye-movement sleep in rats. Brain Res Bull 41:293-298.

Lee S, Rivier C (1994) Hypophysiotropic role and hypothalamic gene expression of corticotropin-releasing factor and vasopressin in rats injected with interleukin- $1 \beta$ systemically or into the brain ventricles. J Neuroendocrinol 6:217-224.

Lee S, Rivier C (1997) An initial, three-day long treatment with alcohol induces a long-lasting phenomenon of selective tolerance in the activity of the rat hypothalamic-pituitary-adrenal axis. J Neurosci $17: 8856-8866$

Lee S, Rivier C (1998) Interaction between corticotropin-releasing factor and nitric oxide in mediating the response of the rat hypothalamus to immune and non-immune stimuli. Mol Brain Res 57:54-62.

Lee S, Rivier C, Torres G (1994) Induction of c-fos and CRF mRNA by MK-801 in the parvocellular paraventricular nucleus of the rat hypothalamus. Mol Brain Res 24:192-198.

Lee S, Barbanel G, Rivier C (1995) Systemic endotoxin increases steadystate gene expression of hypothalamic nitric oxide synthase: comparison with corticotropin-releasing factor and vasopressin gene transcripts. Brain Res 705:136-148.

Li H-Y, Sawchenko PE (1998) Hypothalamic effector neurons and extended circuitries activated in "neurogenic" stress: a comparison of footshock effects exerted acutely, chronically, and in animals with controlled glucocorticoid levels. J Comp Neurol 393:244-266.

Li Y-W, Dampney R (1994) Expression of Fos-like protein in brain following sustained hypertension and hypotension in conscious rabbits. Neuroscience 61:613-634.

Liu H, Terrell ML, Bui V, Summy-Long JY, Kadekaro M (1998) Nitric oxide control of drinking, vasopressin and oxytocin release and blood pressure in dehydrated rats. Physiol Behav 63:763-769.

Loewy A (1990) Central autonomic pathways. In: Central regulation of autonomic functions (Loewy A, Spyer K, eds), pp 88-103. New York: Oxford.

Maness LM, Kastin AJ, Farrell CL, Banks WA (1998) Fate of leptin after intracerebroventricular injection into the mouse brain. Endocrinology 139:4556-4562.

Marcilhac A, Siaud P (1996) Regulation of the adrenocorticotrophin response to stress by the central nucleus of the amygdala in rats depends upon the nature of the stressor. Exp Physiol 81:1035-1038.

McCann SM, Kumura M, Karanth S, Yu WH, Rettori V (1997) Nitric oxide controls the hypothalamic-pituitary response to cytokines. Neuroimmunomodulation 4:98-106.

Mohr E, Richer R (1990) Sequence analysis of the promoter region of the rat vasopressin gene. FEBS Lett 260:305-308.

Morgan JI, Curran T (1991) Stimulus-transcription coupling in the nervous system: involvement of the inductible proto-oncogenes fos and jun. Annu Rev Neurosci 14:421-451.

Morimoto A, Watanabe T, Morimoto K, Nakamori T, Murakami N (1991) Possible involvement of prostaglandins in psychological stressinduced responses in rats. J Physiol (Lond) 443:421-429.

Nemeroff CB (1996) The corticotropin-releasing factor (CRF) hypothesis of depression: new findings and new directions. Mol Psychiat $1: 336-342$.

Nurminen M-L, Vapaatalo H (1996) Effect of intracerebroventricular and intravenous administration of nitric oxide donors on blood pressure and heart rate in anaesthetized rats. Br J Pharmacol 119:1422-1426.

Ota M, Crofton JT, Festavan GT, Share L (1993) Evidence that nitric oxide can act centrally to stimulate vasopressin release. Neuroendocrinology 57:955-959. 
Rivest S, Rivier C (1994) Stress and interleukin- $1 \beta$-induced activation of c-fos, NGFI- $\beta$ and CRF gene expression in the hypothalamic PVN: comparison between Sprague-Dawley, Fisher-344 and Lewis rats. J Neuroendocrinol 6:101-117.

Rivier C (1994) Endogenous nitric oxide participates in the activation of the hypothalamic-pituitary-adrenal axis by noxious stimuli. Endocr $\mathbf{J}$ 2:367-373.

Rivier C (1995) Blockade of nitric oxide formation augments adrenocorticotropin released by blood-borne interleukin-1 $\beta$ : role of vasopressin, prostaglandins, and $\alpha 1$-adrenergic receptors. Endocrinology 136:3597-3603.

Rivier CL, Plotsky PM (1986) Mediation by corticotropin-releasing factor (CRF) of adenohypophysial hormone secretion. Annu Rev Physiol 48:475-494.

Rivier C, Shen G (1994) In the rat, endogenous nitric oxide modulates the response of the hypothalamic-pituitary-adrenal axis to interleukin$1 \beta$, vasopressin and oxytocin. J Neurosci 14:1985-1993.

Rivier C, Vale W (1991) Stimulatory effect of interleukin-1 on ACTH secretion in the rat: is it modulated by prostaglandins? Endocrinology 129:384-388

Rothe F, Canzler U, Wolf G (1998) Subcellular localization of the neuronal isoform of nitric oxide synthase in the rat brain: a critical evaluation. Neuroscience 83:259-269.

Salvemini D, Misko TP, Masferre JL, Seibert K, Currie MG, Needleman P (1993) Nitric oxide activates cyclooxygenase enzymes. Proc Natl Acad Sci USA 90:7240-7244.

Sandi C, Guaza C (1995) Evidence for a role of nitric oxide in the corticotropin-releasing factor release induced by interleukin- $1 \beta$. Eur J Pharmacol 274:17-23.

Satta M, Jacobs R, Kaltas G, Grossman A (1998) Endotoxin induces interleukin- $1 \beta$ and nitric oxide mRNA in rat hypothalamus and pituitary. Neuroendocrinology 67:109-116.

Sautebin L, Islenti A, Ianaro A, Rosa MD (1995) Modulation by nitric oxide of prostaglandin biosynthesis in the rat. $\mathrm{Br} \mathrm{J}$ Pharmacol 114:323-328.

Sawchenko PE, Brown ER, Chan RKW, Ericsson A, Li H-Y, Roland BL, Kovacs KJ (1996) The paraventricular nucleus of the hypothalamus and the functional neuroanatomy of visceromotor responses to stress. In: Emotional motor system (Holstege G, Bandler R, Saper CB, eds), pp 201-222. Amsterdam: Elsevier Science.

Siaud P, Mekaouche M, Ixart G, Balmefrezol M, Givalois L, Barbanel G, Assenmacher I (1994) A subpopulation of corticotropin-releasing hormone neurosecretory cells in the paraventricular nucleus of the hypothalamus also contain NADPH-diaphorase. Neurosci Lett 170:51-54.

Snyder SH, Dawson TM (1995) Nitric oxide and related substances as neural messengers. In: Psychopharmacology: the fourth generation of progress (Bloom FE, Kupfer DJ, eds), pp 609-618. New York: Raven.

Spyer K (1990) The central nervous organization of reflex circulatory control. In: Central regulation of autonomic functions. (Loewy A, Spyer K, eds), pp 168-188. New York: Oxford UP.
Stokes PE, Sikes CR (1991) Hypothalamic-pituitary-adrenal axis in psychiatric disorders. Annu Rev Med 42:519-531.

Swanson LW (1991) Biochemical switching in hypothalamic circuits mediating responses to stress. In: Progress in brain research (Holstege G, ed), pp 181-200. Amsterdam: Elsevier Science.

Tanaka M, Ikeda T, Hayashi S, Iijima N, Amaya F, Hisa Y, Ibata Y (1997) Nitrergic neurons in the medial amygdala project to the hypothalamic paraventricular nucleus of the rat. Brain Res 777:13-21.

Tassorelli C, Joseph SA, Nappi G (1997) Neurochemical mechanisms of nitroglycerin-induced neuronal activation in rat brain: a pharmacological investigation. Neuropharmacology 36:1417-1424.

Torres G, Lee S, Rivier C (1993) Ontogeny of the rat hypothalamic nitric oxide synthase and colocalization with neuropeptides. Mol Cell Neurosci 4:155-163.

Tsuchiya T, Kishimoto J, Koyama J, Ozawa T (1997) Modulatory effect of L-NAME, a specific nitric oxide synthase (NOS) inhibitor, on stress-induced changes in plasma adrenocorticotropic hormone (ACTH) and corticosterone levels in rats: physiological significance of stress-induced NOS activation in hypothalamic-pituitary-adrenal axis. Brain Res 776:68-74.

Turnbull AV, Rivier C (1996) Corticotropin-releasing factor, vasopressin and prostaglandins mediate, and nitric oxide restrains, the hypothalamic-pituitary-adrenal response to acute local inflammation in the rat. Endocrinology 137:455-463.

Turnbull A, Kim C, Lee S, Rivier C (1998) Influence of carbon monoxide, and its interaction with nitric oxide, on the ACTH response of the intact rat to a physico-emotional stress. J Neuroendocrinol 10:793-802.

Vanhatalo S, Soinila S (1995) Nitric oxide synthase in the hypothalamopituitary pathways. J Chem Neuroanat 8:165-173.

Villar M, Ceccatelli S, Rönnqvist M, Hökfelt T (1994) Nitric oxide synthase increases in hypothalamic magnocellular neurons after salt loading in the rat. An immunohistochemical and in situ hybridization study. Brain Res 644:273-281.

Vincent SR (1994) Nitric oxide: a radical neurotransmitter in the central nervous system. Prog Neurobiol 42:129-160.

Vincent SR (1995) Localization of nitric oxide neurons in the central nervous system. In: Nitric oxide in the nervous system (Vincent SR, ed), pp 83-102. New York: Academic.

Watts AG (1996) The impact of physiological stimuli on the expression of corticotropin-releasing hormone $(\mathrm{CRH})$ and other neuropeptide genes. Front Neuroendocrinol 17:281-326.

Whitnall MH (1993) Regulation of the hypothalamic corticotropinreleasing hormone neurosecretory system. Prog Neurobiol 40:573-629.

Wilson T, Fahrner T, Johnston M, Milbrandt J (1991) Identification of the DNA binding site for NGFI-B be genetic selection in yeast. Science 252:1296-1300.

Xu JY, Pieper GM, Tseng LF (1995) Activation of a NO-cyclic GMP system by NO donors potentiates $\beta$-endorphin-induced antinociception in the mouse. Pain 63:377-383. 